\title{
Measurement of the Wheelchair-Operating Time Spent by Stroke Patients Using a New Triaxial Accelerometer System
}

\author{
Yoshino Terui1,2*, Takanobu Shioya1, Koichi Hasegawa², Eriko Suto², \\ Atsuyoshi Kawagoshi' ${ }^{3}$, Masahiro Satake1, Sachie Sawamura4, Shunichi Sakata ${ }^{5}$ \\ ${ }^{1}$ Department of Physical Therapy, Akita University Graduate School of Health Sciences, Akita, Japan \\ ${ }^{2}$ Akita Prefectural Center for Rehabilitation and Psychiatric Medicine, Akita, Japan \\ ${ }^{3}$ Akita City General Hospital, Akita, Japan \\ ${ }^{4}$ Brain and Blood Vessels-Akita, Akita, Japan \\ ${ }^{5}$ Kumamoto Technology and Industry Foundations, Kumamoto, Japan \\ Email: ${ }^{*}$ d4914003@wm.akita-u.ac.jp
}

Received 8 July 2014; revised 10 August 2014; accepted 30 September 2014

Copyright (C) 2014 by authors and Scientific Research Publishing Inc.

This work is licensed under the Creative Commons Attribution International License (CC BY).

http://creativecommons.org/licenses/by/4.0/

c) (i) Open Access

\section{Abstract}

Purpose: We investigated the validity of a triaxial accelerometer system for measuring the time spent lying down, sitting, standing, walking, and operating a wheelchair by control subjects and stroke patients in a convalescence ward. Methods: Physical activities were measured using a new triaxial accelerometer system (A-MES; Activity Monitoring and Evaluation System) that consists of two sensors, a station, and analytical software used with a personal computer. In Experiment 1, the times that the healthy subjects $(n=12)$ spent operating a wheelchair, lying down, sitting, standing, and walking were measured both by the A-MES and by videotaping (video time). In Experiment 2, the amounts of time spent by the stroke patients not able to walk without support $(\mathrm{n}=$ 30) as they were lying down, sitting, standing, walking, and operating a wheelchair were measured by the A-MES. Results: The time spent operating a wheelchair measured with the A-MES was significantly correlated with the video time in the healthy subjects. The stroke patients' average times (minutes) of total, operating a wheelchair, lying down, sitting, standing, and walking were $601.0 \pm 18.1,57.1 \pm 28.8,265.0 \pm 86.3,263.3 \pm 60.6,7.8 \pm 7.0$, and $7.7 \pm 6.0$, respectively. Conclusions: The A-MES accurately evaluated the stroke patients' time spent operating a wheelchair. The stroke patients' mean time spent operating a wheelchair over the course of one day was $57.1 \pm$ $28.8 \mathrm{~min}$ in a Center for Rehabilitation.

\section{Keywords}

Stroke, Wheelchairs, Physical Activity

\footnotetext{
*Corresponding author.
}

How to cite this paper: Terui, Y., Shioya, T., Hasegawa, K., Suto, E., Kawagoshi, A., Satake, M., Sawamura, S. and Sakata, S. (2014) Measurement of the Wheelchair-Operating Time Spent by Stroke Patients Using a New Triaxial Accelerometer System. Open Journal of Therapy and Rehabilitation, 2, 147-155. http://dx.doi.org/10.4236/ojtr.2014.24020 


\section{Introduction}

Stroke has been identified as the second leading cause of death worldwide by the World Health Organization (10.8\% mortality rate) [1] and as the fourth leading cause in Japan by the Japanese Ministry of Health, Labour and Welfare (9.9\% mortality rate) [2]. The prevention and treatment of stroke is thus a critical issue. It is also important to evaluate and care for stroke patients who cannot walk by themselves. Improvements in physical activity have been shown to decrease the risk of stroke and to improve stroke patients' quality of life (QOL) [3][7].

Individuals whose walking is not independent often use a wheelchair as a means of transportation. Among hemiplegic stroke patients at the recovery stage, a wheelchair is a common method of locomotion. For stroke patients who can eventually walk independently, operating a wheelchair is a temporary means of ambulation. Operating a wheelchair is a safe and secure activity by which individuals can increase their physical activity by themselves until they can walk with support. Because operating a wheelchair is an important activity of daily living (ADL), it is crucial to evaluate the time that stroke patients spend operating a wheelchair and thus improving their QOL [3]-[5].

However, to our knowledge there have been no reports about the continuous measurement of the time spent operating a wheelchair over a long period. Triaxial accelerometers have been used to obtain measurements of physical activity, providing more objective values than pedometers or questionnaires [8]-[11]. Most of the conventional triaxial accelerometers can only evaluate the strength used to engage in a physical activity; they cannot distinguish the movement of physical activity. We recently developed and described a triaxial accelerometer system with which the time that an individual spends walking, standing, sitting, and lying down over the course of one day can be measured [12]-[14].

We have improved this evaluation system so that it can measure the time spent operating a wheelchair. The primary purpose of the present study was to verify the validity of this triaxial accelerometer system for measuring the time spent operating a wheelchair. The second purpose of this study was to measure the time spent operating a wheelchair as well as lying down, sitting, standing, and walking over the course of one day among stroke patients in a convalescence ward.

\section{Methods}

\subsection{Participants}

Twelve healthy subjects (six males and six females, mean \pm SD age $21.3 \pm 1.2$ yrs) without illness or disability that could impair their movement participated in Experiment 1 (Table 1).

Thirty patients who had had a stroke (16 males and 14 females, $69.1 \pm 10.9$ yrs) in a convalescence ward of the Akita Prefectural Center for Rehabilitation and Psychiatric Medicine participated in Experiment 2 (Table 1). All 30 patients needed to be supported in order to walk, and they all operated a wheelchair to move around the ward. We urged the patients to operate their wheelchairs without help in their everyday activities. The following patients were not included in this experiment: patients with illness or injuries other than stroke that impaired their behavior, those who needed assistance for all ADLs and were recumbent for the entire day except for rehabilitation time, those who declined to participate in the study, and those who did not understand the purpose of the experiment.

This study was reviewed and approved by the Ethics Committees of Akita University Graduate School of Medicine (2012) and Akita Prefectural Center for Rehabilitation and Psychiatric Medicine (2012), and was carried out according to the Declaration of Helsinki [15]. Written consent was obtained from all the participants or their families.

\subsection{Methods}

\subsubsection{Measurement of Physical Activity}

Physical activity was measured using the A-MESTM (Activity Monitoring and Evaluation System), a new triaxial accelerometer system. The A-MES consists of two sensors (each $69 \mathrm{~mm}$ high $\times 44 \mathrm{~mm}$ wide $\times 11.5 \mathrm{~mm}$ deep, weighing $28 \mathrm{~g}$ ), a station, and analytical software used with a personal computer (Figure 1) [14]. These sensors are so small and lightweight that they can be attached to a subject's thigh and chest without disturbing his or her ADLs. The trunk sensor was attached to the chest of the subject (who wore clothing with a pocket), and the 
Table 1. Baseline characteristics of the twelve healthy controls and the thirty stroke patients (mean \pm SD).

\begin{tabular}{ccc}
\hline & Experiment 1 & Experiment 2 \\
Gender(Men/Women) & $6 / 6$ & $16 / 14$ \\
Age, years & $21.3 \pm 1.2$ & $69.1 \pm 10.9$ \\
Hight, cm & $167.9 \pm 6.79$ & $157.9 \pm 9.7$ \\
Weight, kg & $62.7 \pm 14.0$ & $52.3 \pm 9.4$ \\
BMI & $22.1 \pm 3.8$ & $21.0 \pm 3.2$ \\
Cerebral hemorrhage/Cerebral infraction/Subarachnoid hemorrhage & - & $10 / 17 / 3$ \\
Side of cerebrovascular disease (right/left) & - & $14 / 16$ \\
Duration of morbidity, days & & $82.4 \pm 33.7$ \\
\hline
\end{tabular}

BMI: body mass index.

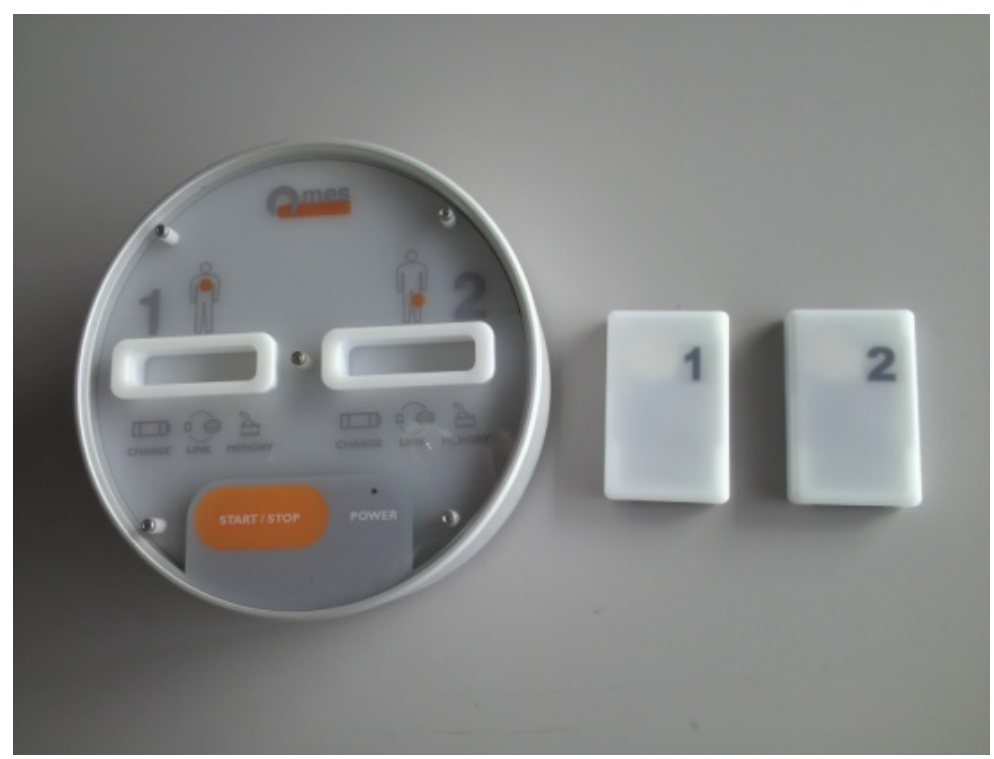

Figure 1. The activity monitoring and evaluation system (A-MES) (right: sensors; left: station).

thigh sensor was attached to the thigh put on bandage and it placed in a pocket. The physical activity data recorded by the two sensors was sent to the A-MES station and analyzed by the A-MES software [14].

The A-MES distinguishes the user's postures from the angles of inclination of the two sensors, and it identifies walking when forward acceleration occurs [14]. In the present study, we improved that A-MES so that it could distinguish the operation of a wheelchair when the forward acceleration signal in the sitting position was detected (Figure 2). The actual waveform of the acceleration signals from the chest and thigh sensors and the way that the A-MES detects the operation of a wheelchair are illustrated in Figure 3.

\subsubsection{Experiment 1}

Experiment 1-1. Each of the healthy control subjects drove a wheelchair for 5 min while wearing the two sensors. Each wheelchair operation session was videotaped with time recording by a digital camera (COOLPIX S6200). One wheelchair was used by all of the control subjects. Six subjects operated the wheelchair using the left arm and leg as the "unaffected" arm and leg, with the right foot of the "affected" leg up on the wheelchair's footplate. The other six subjects used the right arm and leg and with the left foot up on the footplate. The subjects operated the wheelchairs indoors, and the operating speed was kept within the subjects' comfort range. The 


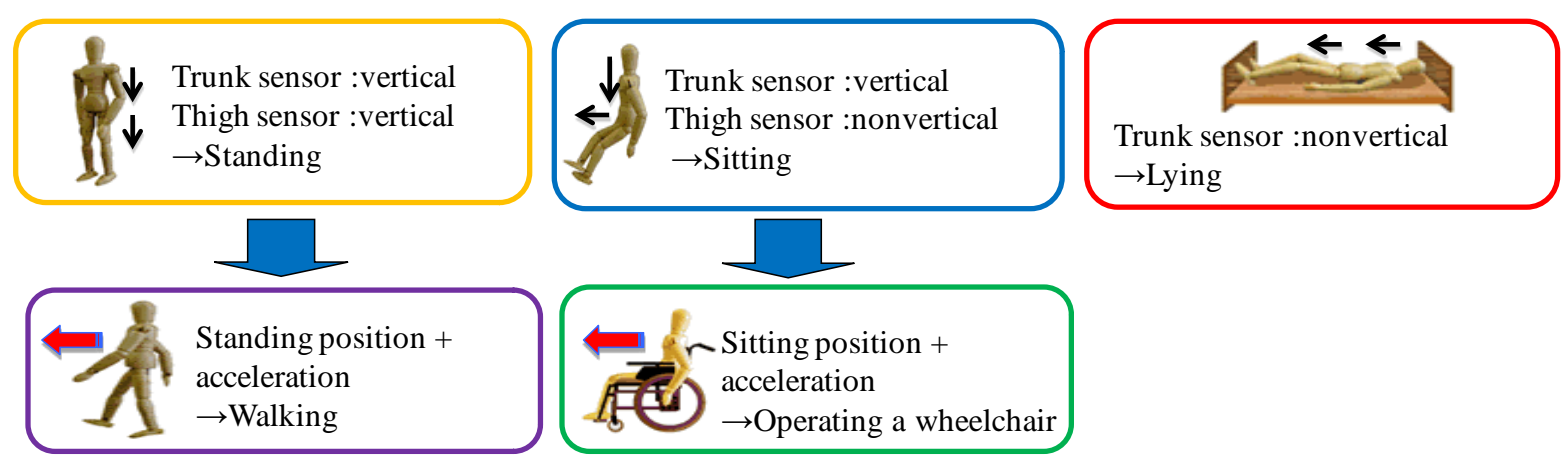

Figure 2. Discrimination of each posture and movement by the A-MES.

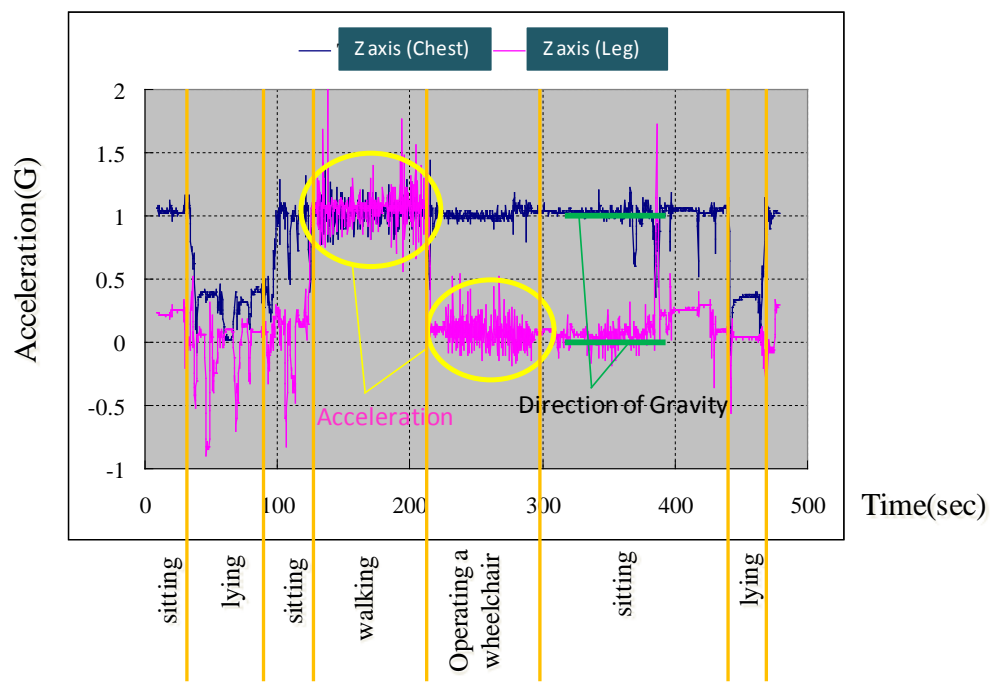

Figure 3. Actual output of waveforms from the A-MES.

courses and the distance that each subject drove the wheelchair were decided by the subjects themselves, and their movements were videotaped.

Experiment 1-2. Each of the 12 healthy control subjects was videotaped lying down, sitting, standing, walking and operating a wheelchair. The time of each movement was set at 5 min. The subjects walked at a normal speed (2 - $4 \mathrm{~km} / \mathrm{hr})$. Six subjects operated the wheelchair using the left arm and leg as the unaffected arm and leg, and the other six subjects used the right arm and leg, as in Experiment 1-1. One wheelchair was used by all of the control subjects. The speed of operating the wheelchair was set at a comfortable speed for each subject. They drove the wheelchairs indoors, and the operating speed was kept within their comfort range. The subjects decided the courses and the distances themselves, and their movements were videotaped by the examiner. The state of the five different postures and movements including the times spent were recorded on the videotape. The order for accomplishing each movement was decided by the subjects themselves, while the timing for changing movements was directed by the examiner.

\subsubsection{Experiment 2}

The amounts of time spent by the stroke patients as they were lying down, sitting, standing, walking, and operating a wheelchair were measured by the A-MES. The patients each used a wheelchair that they found comfortable. The time measured using the A-MES was 12 h (from 7 a.m. to 7 p.m.) in principle. Because the A-MES sensors were removed when the patients bathed, a length of the time corresponding to the patient's bathing time was added after 7 p.m. The stroke patients' daily movements were measured for consecutive 7 days, and the activity time of each posture and movement over the 7 days was averaged into $12 \mathrm{~h}$ in one day. The times spent in physical therapy (PT time) and occupational therapy (OT time) were excluded from the activity time measured. 


\subsection{Statistical Analysis}

The correlation between the time measured by the A-MES (A-MES time) and the time measured by the videotape (video time) was examined using Pearson's product-moment correlation coefficient, calculated with PASW Statistics 18 (SPPS, Quarry Bay, Hong Kong). To test the validity of the A-MES, we used the Bland-Altman analysis method [16] to compare the total time spent in each posture or movement type as measured by both the A-MES and the videotape in Experiment 1. We also calculated the tolerance level of the error in the population (limit of agreement; LOA) [16] and the minimal detectable change of the $95 \%$ confidence interval (MDC ${ }_{95}$ ) to identify the clinically permissible level [16].

\section{Results}

In Experiment 1-1, the time the healthy controls spent operating a wheelchair measured with the A-MES was significantly correlated with the video time $(\mathrm{p}<0.05)$. In Experiment $1-2$, the times spent by the healthy controls at sitting, standing, and operating a wheelchair measured with the A-MES were significantly correlated with the video time (Table 2).

The mean difference between the A-MES time and video time spent operating a wheelchair was $4.50 \pm 6.68 \mathrm{~s}$ in Experiment 1-1. The mean differences between the A-MES time and video time spent sitting, standing and operating a wheelchair were $10.60 \pm 16.16,0.83 \pm 1.99$ and $11.30 \pm 19.82 \mathrm{~s}$, respectively in Experiment 1-2. There was no fixed bias in the wheelchair-operating time measured by the A-MES in Experiment 1-1 or in the times spent sitting, standing and operating a wheelchair in Experiment 1-2 because the 95\% confidence interval (95\%CI) included 0 (Table 2).

In this study, we calculated the t-value from the actual measurements using a correlation coefficient. The $\mathrm{t}$-value in the degree of freedom " 10 " was 2.228. The t-values measured were -1.688 (operating a wheel chair in Experiment 1), -1.910 (sitting), -1.880 (standing), and -0.441 (operating a wheel chair in Experiment 2), and other (lying down and walking), all of which were less than 2.228, suggesting that the proportional bias did not exist (Table 2). The Bland-Altman plot of Experiment 1-1 is shown in Figure 4, and the plot of Experiment 1-2 is given in Figure 5. There were no significant differences in the times spent lying down and walking measured with the A-MES and the corresponding times measured with the videotape in Experiment 1-2 (Table 2).

The total measured time of the stroke patients over one day was $601.0 \pm 18.1 \mathrm{~min}$, and that excluding PT time and OT time was $119.0 \pm 18.1 \mathrm{~min}$. We also found that the time spent lying down over the course of one day was $265.0 \pm 86.3 \mathrm{~min}$; that spend sitting was $263.3 \pm 60.6 \mathrm{~min}$, standing $7.8 \pm 7.0 \mathrm{~min}$, walking $7.7 \pm 6.0 \mathrm{~min}$ and operating a wheelchair $57.1 \pm 28.8 \mathrm{~min}$ (Table 3).

\section{Discussion}

In the Bland-Altman analysis method, if the 95\%CI does not interlay 0, there is a positive and negative bias in

Table 2. Validity of measurement of each movement or posture by A-MES.

\begin{tabular}{|c|c|c|c|c|c|c|c|c|c|}
\hline & & \multirow{2}{*}{\multicolumn{2}{|c|}{$\begin{array}{l}\text { Pearson's product-moment } \\
\text { correlation coefficient }\end{array}$}} & \multicolumn{6}{|c|}{ Bland-Altman method } \\
\hline & & & & \multicolumn{2}{|c|}{ Fixed bias } & \multicolumn{2}{|c|}{ Proportional bias } & \multirow[t]{2}{*}{ LOA } & \multirow[t]{2}{*}{ MDC $_{95}$} \\
\hline & & $\begin{array}{l}\text { Correlation } \\
\text { coefficient }\end{array}$ & $\mathrm{p}$ & $\begin{array}{l}\text { 95\% confidence } \\
\text { interval }\end{array}$ & $\begin{array}{l}\text { Existence } \\
\text { of bias }\end{array}$ & $\begin{array}{l}\mathrm{t} \text {-value from } \\
\text { measured value }\end{array}$ & $\begin{array}{l}\text { Existence } \\
\text { of bias }\end{array}$ & & \\
\hline Experiment 1 & $\begin{array}{l}\text { operating a } \\
\text { wheelchair }\end{array}$ & 0.969 & 0.000 & $-0.94-9.94$ & no & -1.688 & no & $-0.22-9.22$ & 13.09 \\
\hline \multirow{5}{*}{ Experiment 2} & lying & 1.000 & 0.000 & 0.00 & no & - & no & 0.00 & 0.00 \\
\hline & sitting & 0.742 & 0.014 & $-0.79-21.99$ & no & -1.910 & no & $-1.79-22.99$ & 31.67 \\
\hline & standing & 0.997 & 0.000 & $-0.42-2.09$ & no & -1.880 & no & $-0.90-2.57$ & 3.91 \\
\hline & $\begin{array}{l}\text { operating a } \\
\text { wheelchair }\end{array}$ & 0.726 & 0.027 & $-2.67-25.27$ & no & -0.441 & no & $-5.95-28.55$ & 38.85 \\
\hline & walking & 1.000 & 0.000 & 0.00 & no & - & no & 0.00 & 0.00 \\
\hline
\end{tabular}

LOA: limits of agreement; $\mathrm{MDC}_{95}$ : minimal detectable change $95 \%$; degree of freedom $\mathrm{n}-2=10$; $\mathrm{t}$ value (the level of significant was $\mathrm{p}<0.05$ ) 2.228 . 
Table 3. Time spent in each posture or movement.

\begin{tabular}{cc}
\hline & Time, minutes \\
\hline Lying & $265.0 \pm 86.3$ \\
Sitting & $263.3 \pm 60.6$ \\
Standing & $7.8 \pm 7.0$ \\
Walking & $7.7 \pm 6.0$ \\
Operating a wheelchair & $57.1 \pm 28.8$ \\
\hline
\end{tabular}

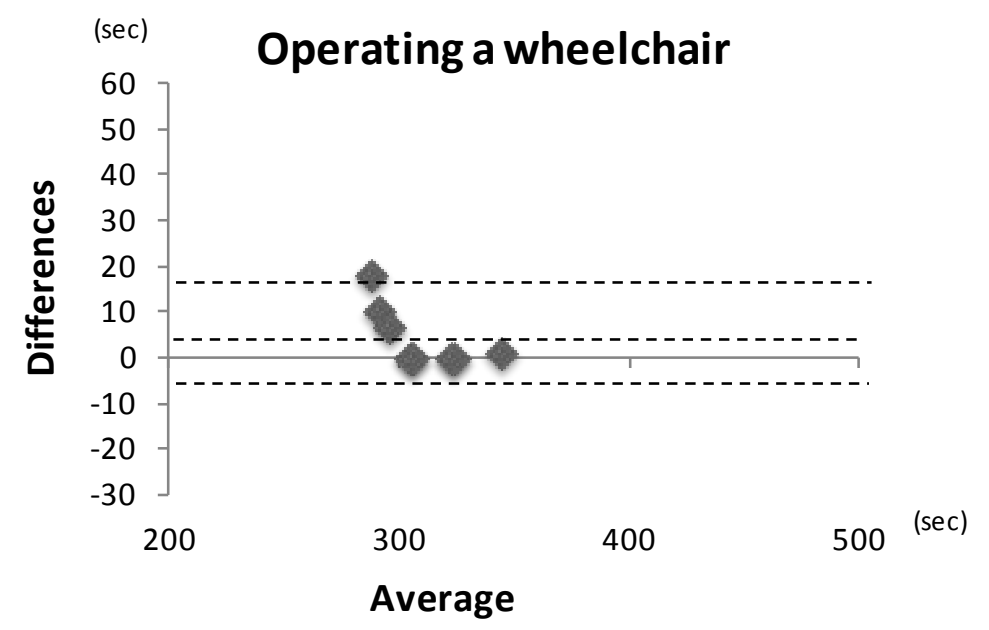

Figure 4. Validity of the measurement of the time spent operating a wheelchair by healthy subjects (Bland-Altman analysis). The mean values of all data (solid line), +1.96 SD (upper dashed line) and -1.96 SD (lower dashed line) are shown.
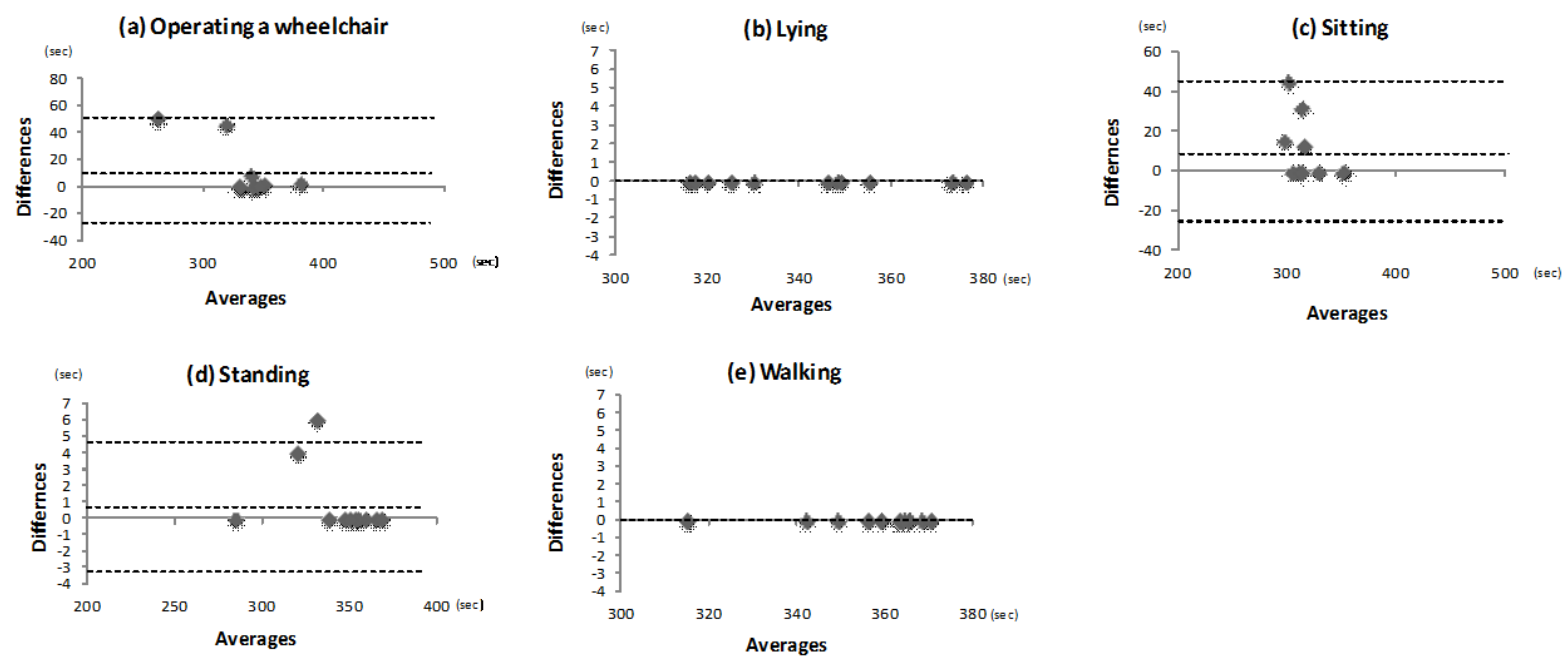

Figure 5. Validity of the measurement of each posture and movement by healthy subjects by Bland-Altman analysis. Mean values of all data (solid lines), +1.96 SD (upper dashed lines) and -1.96 SD (lower dashed lines) are shown.

the errors, suggesting that a fixed error exists [16]. In the present results, because the 95\%CI values for the times spent sitting, standing and operating a wheelchair interlaid 0 , there was no the fixed error in measuring these movements in these experiments. If the " $x$ " values increase and the " $y$ " values increase more, suggesting the ex- 
istence of a proportional bias, the Bland Altman plot becomes fan-shaped [16]. In the present study, there was no proportional error because the absolute t-value obtained from the measured value was smaller than the t-value at the $5 \%$ significance level of degrees of freedom “n - 2" [16]. Thus, as a systematic error was not found between the time spent operating a wheelchair measured by the A-MES and that measured by the videotape, the validity of the measurement of wheelchair-operating time by the A-MES was confirmed.

Several studies [17]-[19] have shown the validity of accelerometers for measuring physical activity using the Bland-Altman analysis method. Taraldsen et al. [17] showed that measurement using the ActivPal ${ }^{\mathrm{TM}}$ distinguished the sitting position from the upright position. Fulk et al. [18] reported that measurements using the Smartshoe ${ }^{\mathrm{TM}}$ could discriminate sitting, standing and walking. Lugade et al. [19] developed equipment comprised of triaxial accelerometers that could distinguish various movements (lying down, sitting, standing, walking, jumping and running).

As stated above, since in Experiment 1 a systematic error did not exist when the Bland-Altman analysis method was used, our present results demonstrate that the A-MES could measure not only the time spent lying down, sitting, standing and walking, but also the time spent operating a wheelchair. Small equipment [20]-[22] associated with accelerometers has been used to measure the physical activities of individuals without disturbing their ADLs. The triaxial accelerometer system in the A-MES is advantageous because the sensors in A-MES are small and light.

In Experiment 1-2, there were no significant differences between the times spent lying down, sitting, standing, walking and operating a wheelchair with the A-MES and the corresponding times measured by videotape. The present data suggest the validity of our triaxial accelerometer system for measuring the time spent at the various activities in the healthy subjects. However, the validity of the triaxial accelerometer system for measuring the time spent at the various activities and operating a wheelchair among stroke patients must be evaluated in a future study.

Here we used the A-MES to measure the times spent by stroke patients in physical activities including operating a wheelchair. The total activity time measured excluding the PT and OT (rehabilitation) time was approx. $10 \mathrm{~h}$, and the time spent operating a wheelchair was $57.1 \mathrm{~min}$ over the course of the day. Since the time spent lying down was $265.0 \mathrm{~min}$ and that spent sitting was $263.3 \mathrm{~min}$, these hospitalized stroke patients' active time and time spent in a wheelchair were both very short.

The exercise intensity needed to operate a wheelchair has been shown to be lower than that for walking, but higher than that needed for sitting [23]. For stroke patients who cannot walk independently, operating a wheelchair may be the only means of ambulation. Higher levels of physical activity in stroke survivors have shown to be related to better QOL [24], and an increase in the time spent operating a wheelchair could lead to improved QOL. Thus, to evaluate the physical activity in the ADLs among stroke patients, the accurate measurement of not only the time spent sitting, standing and walking but also the time spent operating a wheelchair is important.

In this study, we found that the stroke patients' time spent operating a wheelchair was relatively short. This was because operating a wheelchair in the hospital ward was limited to the movement for meals, toileting, bathing and so on. Further research is necessary to examine the relationships among the time spent operating a wheelchair, physical functions, and ADLs in stroke patients using wheelchairs. Moreover, it is important that the time spent operating a wheelchair at home by stroke patients is evaluated in detail after the patients are discharged from the hospital.

\section{Conclusion}

The A-MES is a wearable activity monitor that is composed of a triaxial accelerometer system. The findings obtained in the present study indicate that the A-MES was able to accurately evaluate the time that stroke patients spent operating a wheelchair. In this patient population, the mean time spent operating a wheelchair over the course of one day was $57.1 \mathrm{~min}$, which was shorter than the rehabilitation time in a convalescence ward.

\section{Acknowledgements}

We thank all the staff of the Akita Prefectural Center for Rehabilitation and Psychiatric Medicine's Department of Functional Training, Akita City General Hospital's Department of Rehabilitation, and professors of the Akita University Graduate School of Health Sciences for their advice and support during the study. 


\section{Conflict of Interest Statement}

The Authors declare that there is no conflict of interest.

\section{Funding}

This research received no specific grant from any funding agency in the public, commercial, or not-for-profit sectors.

\section{References}

[1] World Health Organization (2011) The 10 Leading Causes of Death by Broad Income Group (2008). http://www.who.int/mediacentre/factsheets/fs310/en/index.html.

[2] Ministry of Health, Labor and Welfare (2012). http://www.mhlw.go.jp/toukei/saikin/hw/jinkou/geppo/nengai11/dl/gaikyou23.pdf

[3] Lee, C.D., Folsom, A.R. and Blair, S.N. (2003) Physical Activity and Stroke Risk: A Meta-Analysis. Stroke, 34, 2475-2481. http://dx.doi.org/10.1161/01.STR.0000091843.02517.9D

[4] Wendel-Vos, G.C., Schuit, A.J., Feskens, E.J., Boshuizen, H.C., Verschuren, W.M., Saris, W.H. and Kromhout, D. (2004) Physical Activity and Stroke. A meta-analysis of observational data. International Journal of Epidemiology, 33, 787-798. http://dx.doi.org/10.1093/ije/dyh168

[5] Lee, I.M. and Paffenbarger Jr., R.S. (2000) Association of Light, Moderate, and Vigorous Intensity Physical Activity with Longevity: The Harvard Alumni Health Study. American Journal of Epidemiology, 151, 293-299. http://dx.doi.org/10.1093/oxfordjournals.aje.a010205

[6] Oguma, Y. and Shinoda-Taqawa, T. (2004) Physical Activity Decreases Cardiovascular Disease Risk in Woman: Review and Meta-Analysis. American Journal of Preventive, 26, 407-418. http://dx.doi.org/10.1016/j.amepre.2004.02.007

[7] Goldstein, L.B., Bushnell, C.D., Adams, R.J., Appel, L.J., Braun, L.T., Chaturvedi, S., Creaqer, M.A., Culebras, A., Eckel, R.H., Hart, R.G., Hinchey, J.A., Howard, V.J., Jauch, E.C., Levine, S.R., Meschia, J.F., Moore, W.S., Nixon, J.V. and Pearson, T.A., American Heart Association Stroke Council, Council on Cardiovascular Nursing, Council on Epidemiology and Prevention, Council for High Blood Pressure Research, Council on peripheral Vascular Disease, Interdisciplinary Council on Quality of Care and Outcome (2011) Guidelines for the Primary Prevention of Stroke: A Guideline for Healthcare Professionals from the American Heart Association/American Stroke Association. Stroke, 42, 517-584. http://dx.doi.org/10.1161/STR.0b013e3181fcb238

[8] Shah, R.C., Buchman, A.S., Leurqans, S., Boyle, P.A. and Bennett, D.A. (2012) Association of Total Daily Physical Activity with Disability in Community-Dwelling Older Persons: A Prospective Cohort Study. BMC Geriatrics, 12, 63. http://dx.doi.org/10.1186/1471-2318-12-63

[9] Mansfield, A., Wong, J.S., Bayley, M., Biasin, L., Brooks, D., Brunton, K., Howe, J.A., Inness, E.L., Jones, S., Lymburner, J., Mileris, R. and Mcllroy, W.E. (2013) Using Wireless Technology in Clinical Practice: Dose Feedback of Daily Walking Activity Improve Walking Outcomes of Individuals Receiving Rehabilitation Post-Stroke? Study Protocol for a Randomized Controlled Trial. BMC Neurology, 13, 93. http://dx.doi.org/10.1186/1471-2377-13-93

[10] Dobkin, B.H., Xu, X., Batalin, M., Thomas, S. and Kaiser, W. (2011) Reliability and Validity of Bilateral Ankle Accelerometer Algorithms for Activity Recognition and Walking Speed after Stroke. Stroke, 42, 2246-2250

[11] Sakamoto, K., Nakamura, T., Sajima, Y., Miyama, T., Yamanaka, M. and Tajima, F. (2008) Physical Activities and Steps in Daily Living after Stroke. The Journal of the Wakayama Medical Society, 59, 67-72.

[12] Sakata, S., Nojiri, S. and Nagata, M. (2004) The Improvement on the A-MES (Activity Monitoring and Evaluation System) for Commercialization. Den-o-ken Technical Report, 14, 10-14.

[13] Miura, S., Satake, M., Tamura, Y., Ikeda, M., Kawagoshi, A., Sugawara, K., Takahashi, H., Homma, M., Sakata, S. and Shioya, T. (2013) Evaluation of Walking Time According to Walking Speed Using a Triaxial Accelerometer System. Japanese Journal of Comprehensive Rehabilitation Science, 4, 73-79.

[14] Kawagoshi, A., Kiyokawa, N., Sugawara, K., Takahashi, H., Sakata, S., Miura, S., Sawamura, S., Satake, M. and Shioya, T. (2013) Quantitative Assessment of Walking Time and Postural Change in Patients with COPD Using a New Triaxial Accelerometer System. International Journal of Chronic Obstructive Pulmonary, 8, 397-404. http://dx.doi.org/10.2147/COPD.S49491

[15] World Medical Association Declaration of Helsinki (2013) Ethical Principles for Medical Research Involving Human Subjects. JAMA, 31, 2191-2194.

[16] Bland, J.M. and Altman, D.G. (1986) Statistical Methods for Assessing Agreement between Two Methods of Clinical 
Measurement. Lancet, 327, 307-310. http://dx.doi.org/10.1016/S0140-6736(86)90837-8

[17] Taraldsen, K., Askim, T., Sletvold, O., Einarsen, E.K., Bjastad, K.G., Indredavik, B. and Helbostad, J.L. (2011) Evaluation of a Body-Worn Sensor System to Measure Physical Activity in Older People with Impaired Function. Physical Therapy, 91, 277-285. http://dx.doi.org/10.2522/ptj.20100159

[18] Fulk, G.D., Edgar, S.R., Bierwirth, R., Hart, P., Lopez-Meyer, P. and Sazonov, E. (2012) Indentifying Activity Levels and Steps of People with Stroke Using a Novel Shoe-Based Sensor. Journal Neurologic Physical Therapy, 36, 100-107. http://dx.doi.org/10.1097/NPT.0b013e318256370c

[19] Lugade, V., Fortune, E., Morrow, M. and Kaufman, K. (2013) Validity of Using Tri-Axial Accelerometers to Measure Human Movement. Part 1: Posture and Movement Detection. Medical Engineering \& Physics, 36, 169-176. http://dx.doi.org/10.1016/j.medengphy.2013.06.005

[20] Berlin, J.E., Storti, K.L. and Brach, J.S. (2006) Using Activity Monitors to Measure Physical Activity in Free-Living Conditions. Physical Therapy, 86, 1137-1145.

[21] Askim, T., Bernhardt, J., Churilov, L., Fredriksen, K.R. and Indredavik, B. (2013) Changes in Physical Activity and Related Functional and Disability Levels in the First Six Months after Stroke: A Longitudinal Follow-Up Study. Journal of Rehabilitation Medicine, 45, 423-428. http://dx.doi.org/10.2340/16501977-1137

[22] Kramer, S.F., Cumming, T., Churilov, L. and Bernhardt, J. (2013) Measuring Activity Levels at an Acute Stroke Ward: Comparing Observations to a Device. BioMed Research International, 2013, Article ID: 460482. http://dx.doi.org/10.1155/2013/460482

[23] Chae, S.Y. (2012) Comparison of Cardiopulmonary Function Changes during Wheelchair Propulsion: Backrest Angle. Journal of Physical Therapy Science, 24, 355-357. http://dx.doi.org/10.1589/jpts.24.355

[24] Aidar, F.J., de Oliveira, R.J., Silva, A.J., de Matos, D.G., Garrido, N., Hickner, R.C. and Reis, V.M. (2011) The Influence of the Level of Physical Activity and Human Development in the Quality of Life in Survivors of Stroke. Health and Quality of Life Outcomes, 9, 89. http://dx.doi.org/10.1186/1477-7525-9-89 
Scientific Research Publishing (SCIRP) is one of the largest Open Access journal publishers. It is currently publishing more than 200 open access, online, peer-reviewed journals covering a wide range of academic disciplines. SCIRP serves the worldwide academic communities and contributes to the progress and application of science with its publication.

Other selected journals from SCIRP are listed as below. Submit your manuscript to us via either submit@scirp.org or Online Submission Portal.
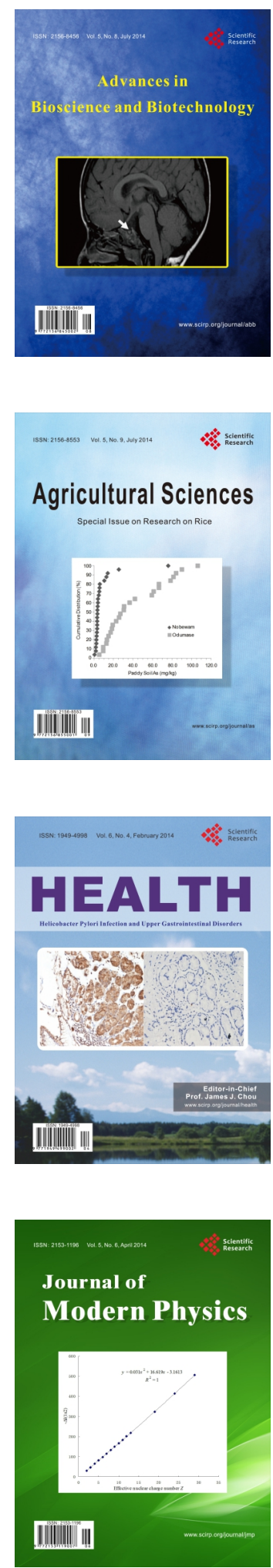
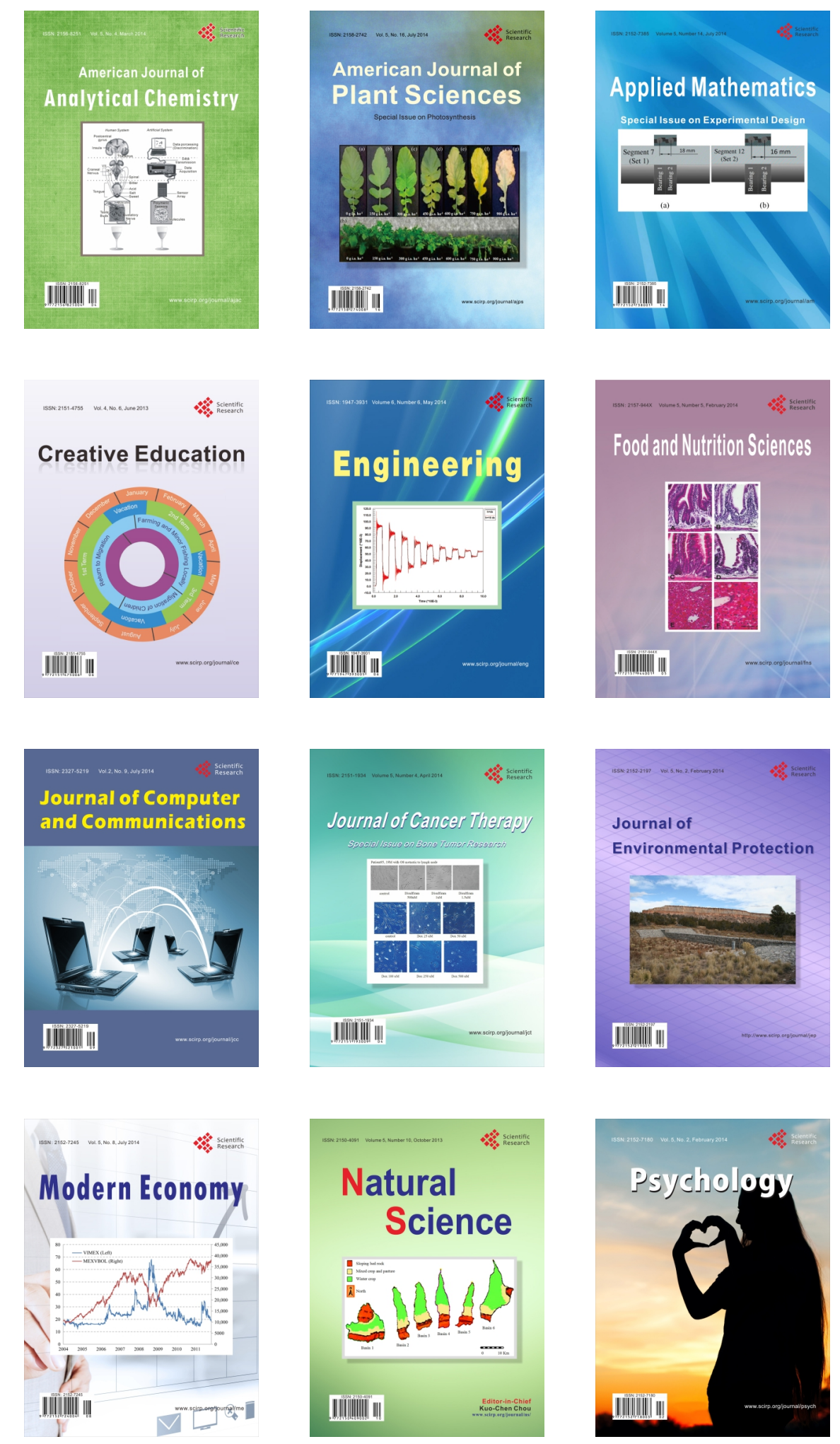